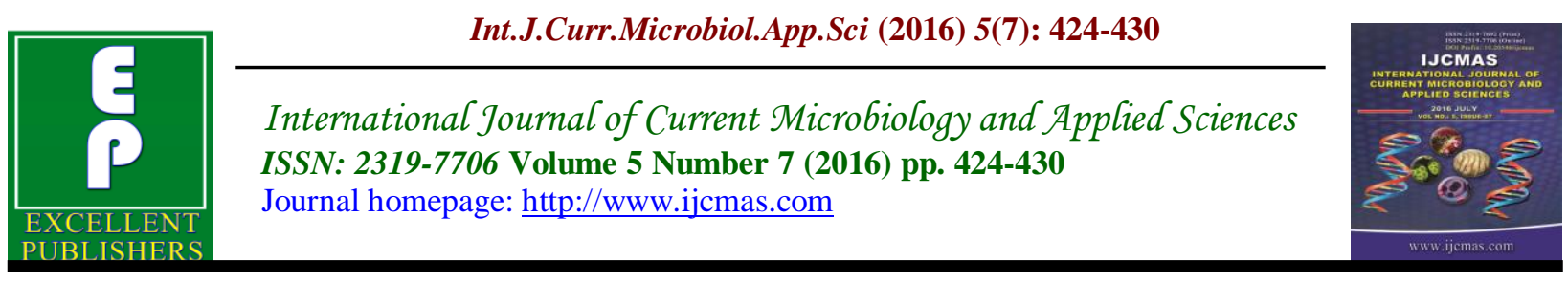

Original Research Article http://dx.doi.org/10.20546/ijcmas.2016.507.046

\title{
Screening of Isolated Marine Bacteria for Multiple Biotechnological Applications
}

\author{
Hala Ezzat Abou El-Hassayeb* \\ Department of Marine Microbiology, National Institute of Oceanography \\ and Fisheries, Alexandria, Egypt \\ *Corresponding author
}

\begin{tabular}{|c|c|}
\hline & A B S T R A C T \\
\hline Keywords & $\begin{array}{l}\text { A total of thirteen bacterial isolates were isolated from Eastern, Western harbors' } \\
\text { of Alexandria and Lake Mariout. The isolates were screened for various }\end{array}$ \\
\hline $\begin{array}{l}\text { Marine isolates, } \\
\text { enzymatic } \\
\text { activity, } \\
\text { biotechnological } \\
\text { applications, } \\
\text { oil degradation. }\end{array}$ & $\begin{array}{l}\text { biotechnological applications such as the ability to produce antibacterial } \\
\text { compounds and extracellular enzymes (including, protease, lipase, amylase and } \\
\text { cellulase), as well as their ability to degrade crude oil and chemical dyes and to } \\
\text { solubilize phosphate. Results revealed that } 9 \text { isolates were protease producers, } 6 \text { of } \\
\text { them showed lipase activity and none of them produced cellulase or amylase. Four } \\
\text { of the isolated bacteria exhibited antibacterial activity against Staphylococcus }\end{array}$ \\
\hline ticle Info & aureus ATCC 25923 and two bacterial isolates against Escherichia coli ATCC \\
\hline $\begin{array}{l}\text { Accepted: } \\
\text { 15 June } 2016 \\
\text { Available Online: } \\
10 \text { July } 2016\end{array}$ & $\begin{array}{l}\text { decolorize and degraded the tested dyes saffranin and crystal violet. Three isolates } \\
\text { showed the potential ability to degrade crude oil. The study has overall concluded } \\
\text { that marine bacteria could serve as potential bio resources for many } \\
\text { biotechnological applications. }\end{array}$ \\
\hline
\end{tabular}

\section{Introduction}

Marine biotechnology is the science in which marine organisms are used in full or partially to make or modify products, to improve plants or animals or to develop microorganisms for specific uses. With the help of different molecular and biotechnological techniques, human has been able to elucidate many biological methods applicable to both aquatic and terrestrial organisms (Jha and Zi-rong, 2004). Marine microbes offer great opportunities for biodiscovery (Bull et al., 2000), as they are not yet fully characterized or evaluated for their potential biotechnological application.
Despite of a huge microbial diversity of marine ecosystem, there is a lack of laboratory cultures of the microbes that are most abundant in the marine environment that severely limits development of biodiscovery research. Research into natural products from the marine environment, including microorganisms, has rapidly increased over the past few years. They are considered highly valuable as they produce various antibiotics and other therapeutically useful compounds with diverse biological activities (Ramesh and Mathivanan, 2009). Marine microorganisms were proven already 
to have many beneficial bioactivities such as production of industrial enzymes (Chatellier et al., 2011; Manasi, 2011). All species have a role in our biosphere. However trying to understand that role is not an easy task. With the help of experimentations we can try to understand the activities of microbes and implement them to our advantage in the industrial field or bioremediation. Marine microorganisms have unique properties since they have to adapt to extreme marine environment conditions such as high or low temperature, alkaline or acidic water, high pressure and limited substrate in the deepsea water. These distinctive characteristics have attracted many researchers to explore in depth since there is the potential of marine microorganisms used in industry (Baharum et al., 2010). In their review, the authors have focused on marine microorganisms that provided biotechnological applications in enzymes industry and pharmaceutical products and also provided an overview of the challenge faced by researchers in order to explore and exploit the marine reservoir. The purpose of the present study was to investigate potential microorganisms present in marine environment which can be utilized for various enzyme processes and biodegradation processes.

\section{Materials and Methods}

\section{Collection of marine water sample}

Collection of marine water samples was carried out from Western and Eastern Alexandria Harbors and Lake Mariout (Egypt). For bacterial isolation, samples were collected in $150 \mathrm{ml}$ previously sterilized glass bottles.

\section{Isolation of marine bacteria}

Marine water bacteria were isolated using nutrient agar. The plates were incubated at $\left(30 \pm 2^{\circ} \mathrm{C}\right)$ for two days. After incubation, well separated colonies were selected and sub-cultured on the nutrient agar.

\section{Production of extracellular enzymes}

Thirteen morphologically distinct bacterial were subjected for the screening of extracellular enzymatic activities namely protease, amylase, lipase and cellulase using simple quantitative plate assay described by Vijayan et al. (2012) as follows:

\section{Protease activity}

Nutrient gelatin medium containing $(\mathrm{g} / \mathrm{l})$ peptone: $5 \mathrm{~g}$, Beef extract: $3 \mathrm{~g}$, gelatin: 120 $\mathrm{g}$, and final $\mathrm{pH}$ was adjusted at 6.8. An 18 hrs old pure culture was streaked on nutrient gelatin medium and were incubated at $30 \pm 2{ }^{\circ} \mathrm{C}$ for $48 \mathrm{hrs}$.

\section{Lipase activity}

Nutrient agar containing butter fat was used for screening bacterial isolates for lipase activity. The cultures were streaked on nutrient agar medium and the plates were incubated at $30 \pm 2^{\circ} \mathrm{C}$ for $24 \mathrm{hrs}$. following incubation, the plates were observed in a UV transilluminator for a clear zone around the colony.

\section{Cellulose activity}

The cultures were streaked on carboxymethyl cellulase agar and the plates were incubated $30 \pm 2^{\circ} \mathrm{C}$ for $24 \mathrm{hrs}$. The plates were then flooded with $10 \% \mathrm{NaCl}$ for $10 \mathrm{~min}$. Clear zone around the reddish background indicates the production of cellulose by the tested bacteria.

\section{Amylase activity}

The bacterial isolates were streaked on starch agar plates containing peptone $(0.1 \%$ 
wt/vol), $\mathrm{NaCl}(0.5 \% \mathrm{wt} / \mathrm{vol})$, agar $(2.0 \%$ $\mathrm{wt} / \mathrm{vol})$, and soluble starch (1\% wt/vol) and final $\mathrm{pH}$ was adjusted at 7.0. Plates were incubated at $32^{\circ} \mathrm{C}$ for $24 \mathrm{hrs}$. A clear zone of hydrolysis after Lugol's Iodine solution addition gave an indication of amylolytic microorganisms.

\section{Antibacterial Activity}

Nutrient agar was prepared and autoclaved and poured in petridishes. Tow bacterial pathogen, Staphylococcus aureus ATCC 25923 and Escherichia coli ATCC 8739 obtained from Marine Microbiology at National Institute of oceanography and fisheries (NIOF). All the thirteen isolates were placed at 4 corners of the petridish as patch inoculums and kept for incubation at $30^{\circ} \mathrm{C}$. After $24 \mathrm{hrs}$, the zone of inhibition around the bacterial colonies was observed if any (Vijayan et al., 2012).

\section{Dyes Degrading Ability}

Nutrient broth (4 ml) was prepared and $1 \mathrm{ml}$ of chosen dye $(0.1 \%$ of crystal violet and saffranin) was added in test tubes and sterilized. Medium was then inoculated with the tested isolate. Control was prepared with $4 \mathrm{ml}$ of nutrient broth added with $1 \mathrm{ml}$ of chosen dye with no added bacteria. Tubes were incubated at $30^{\circ} \mathrm{C}$ for $48 \mathrm{hrs}$ after which they were visually observed for decolorization if any. In addition, the growth of bacteria in the presence of dye was estimated by taking absorbance of the culture broth at $600 \mathrm{~nm}$ in Elico UV Vis Spectrophotometer (Ayed et al., 2009).

\section{Oil Degrading Ability}

The isolates were checked for their oil degrading ability using Bushnell Haas agar medium as described by Singh et al. (2015). The molten medium was tempered at $47 \pm 1^{\circ} \mathrm{C}$ and inoculated with the tested isolate at $1 \%(\mathrm{v} / \mathrm{v})$ and crude oil samples were poured in lid of plates. The plates were incubated at $30 \pm 2^{\circ} \mathrm{C}$ for $48 \mathrm{hrs}$.

\section{Phosphate Solubilization Activity}

For the screening procedure quarter strength of nutrient agar was prepared and $1 \%$ of tricalcium phosphate was added before autoclaving the medium. This resulted in a milky white medium. The medium was poured into petri plates and left to solidify under laminar flow. The bacterial isolates were patched on 4 corners of the plate and incubated at for $7 \mathrm{~d}$ at $30^{\circ} \mathrm{C}$ (Nautiyal and Mehta 2001). A clear zone around the bacterial patches indicates their ability to solublize phosphate in agar medium.

\section{Results and Discussion}

\section{Isolation of Marine Bacteria}

Thirteen marine bacteria ware isolated using nutrient agar. The colonies were distinguished by morphological characters like shape, size, colour, margin, elevation and capacity. The morphologically distinct bacteria were further subcultured on nutrient agar to screen them for various applications.

Thirteen marine bacterial (MB) isolates were isolated using nutrient agar. Eight of them were isolated from Eastern Alexandria harbor and given the following codes (MB1, MB2, MB3, MB4, MB5, MB6, MB7 and MB8). Four other isolates were isolated from Western Alexandria harbor and given codes (MB9, MB10, MB11 and MB12), while the last isolate was recovered from water sample taken from Lake Mariout (MB13). The colonies were distinguished by morphological characters like shape, size, color, margin, elevation and opacity. The morphologically distinct bacteria from nutrient agar were further subculture on nutrient agar to screen them for various potential biotechnological applications. 


\section{Production of Extracellular Enzymes}

The thirteen bacteria were subjected for their ability to produce 4 different enzymatic activities (Table 1). The results revealed that six of them showed positive results for lipase activity and nine were positive for protease activity (Figure1) but none showed the ability to have either amylase or cellulase activity.

The thirteen bacterial isolates were screened for their antibacterial activity against both Staphylococcus aureus ATCC 25923 (Gram positive) and Escherichia coli ATCC 8739 (Gram negative). Among tested isolates, MB2 and MB11 showed potential antibacterial activity against E. coli ATCC 8739, while isolates MB2, MB3, MB4 and MB11 showed antibacterial activity against S. aureus ATCC 25923as shown in Figure 2.

\section{Dyes Degrading Ability}

None of the tested isolates was able to decolorize the tested dyes (crystal violet and saffranin) which may indicate the inability of the marine isolates to degrade hydrocarbons from the dyes which are necessary for growth of bacteria.

\section{Oil Degrading Ability}

The thirteen isolates were tested for their ability to degrade oil using Bushnell and Haas medium containing petrol. Three isolates (MB6, MB8 and MB13) were able to grow and degrade oil, indicating their ability to utilize the oils as a source of carbon.

\section{Phosphate Solubilization Activity}

None of the tested isolates was able to produce a clearance zone around their colony grown for 5 days in tri-calcium phosphate amended medium, indicating that none of them has the ability to solubilize phosphate by an extra-cellularly mechanism.

The marine environment is the largest habitat on Earth, representing more than $70 \%$ of the surface of our planet. Oceans have the greatest extremes of temperature, light and pressure encountered by life (Munn, 2004). These extremes increase biodiversity among marine bacterial ecosystems and make them vary widely in composition and activity. Consequently, marine bacterial ecosystem can be regarded as an excellent source of new bioactive compounds with potential industrial, environmental, pharmaceutical and medical applications (Debnath et al. 2007). Despite a huge microbial diversity, there is a lack of laboratory cultures of the microbes that are most abundant in the environment that severely limits development of biodiscovery research. Baharum et al. (2010) focused on marine microorganisms that provide biotechnological applications in enzymes industry and pharmaceutical products and also provided an overview of the challenge faced by researchers in order to explore and exploit the marine reservoir. In that study, 13 marine bacterial isolates were isolated from marine water samples collected from Eastern, Western harbors' of Alexandria and Lake Mariout. Dionisi et al. (2012) stated that microorganisms may be able to tolerate rapid and repeated fluctuations in environmental conditions including temperature, light and salinity, and are exposed to wave action, ultraviolet radiation, as well as periods of drought. Hence, microbes from such harsh environments may exhibit potential properties which can be exploited for biotechnological applications. There has been a great interest from researchers to explore marine microorganisms as new source of antibacterial compounds as 
increasing resistance of pathogen to present antibiotics. One example of studies that has been carried out is purification and partial characterization of marinocine, a new broadspectrum antibacterial protein produced by Marinomonas mediterranea (Lucas-Elio et al., 2005). Marine microorganisms were proven already to have many beneficial bioactivities such as production of industrial enzymes (Chatellier et al., 2011; Manasi, 2011).

Table.1 Production of extracellular enzymes

\begin{tabular}{|l|c|c|c|c|}
\hline Strain code & Lipase & Protease & amylase & Cellulose \\
\hline MB1 & + & - & - & - \\
\hline MB2 & + & + & - & - \\
\hline MB3 & + & - & - & - \\
\hline MB4 & ++ & - & - & - \\
\hline MB5 & - & + & - & - \\
\hline MB6 & - & + & - & - \\
\hline MB7 & - & + & - & - \\
\hline MB8 & - & + & - & - \\
\hline MB9 & ++ & - & - & - \\
\hline MB10 & - & + & - & - \\
\hline MB11 & ++ & + & - & - \\
\hline MB12 & - & + & - & - \\
\hline MB13 & - & + & - & - \\
\hline
\end{tabular}

Fig.1 Ability of extracellular protease activity of marine isolates exhibited on nutrient gelatin medium. Numbers 1, 2, 3 and 4, refer to isolates MB1, MB2, MB3 and MB4, respectively.

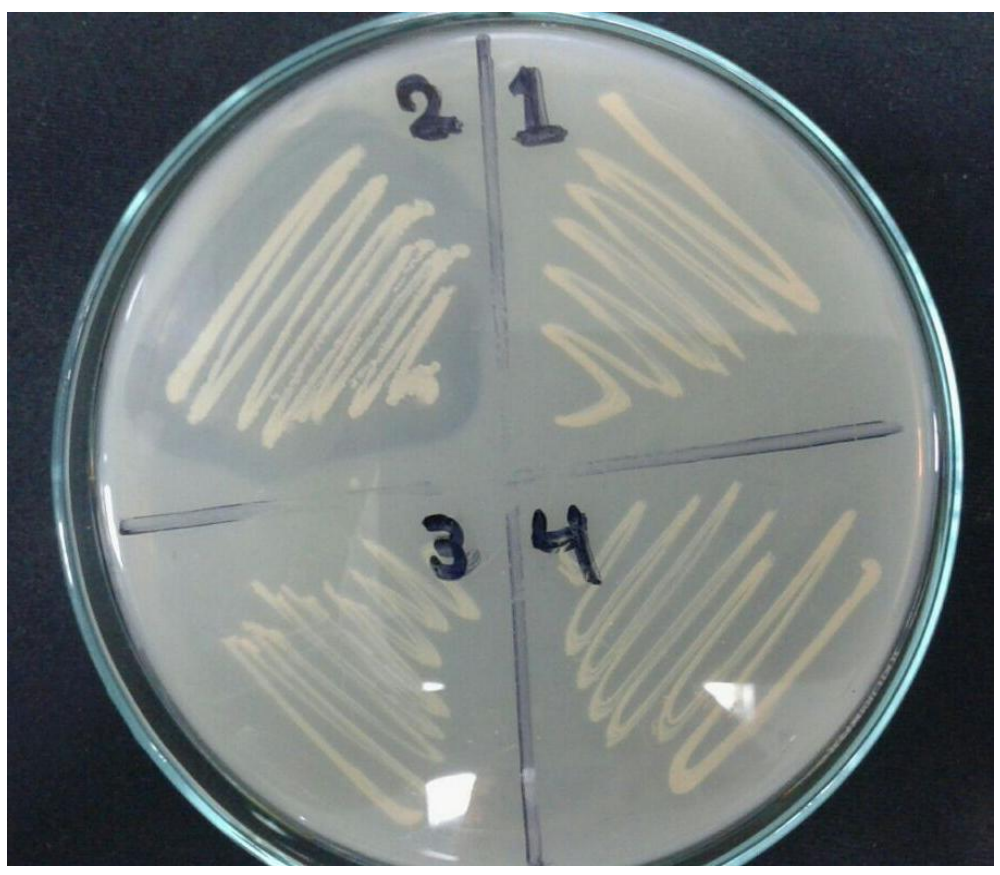


Fig.2 Antibacterial activity of bacterial isolates coded MB2, MB3, MB4 and MB11 against Staphylococcus aureus ATCC 25923.

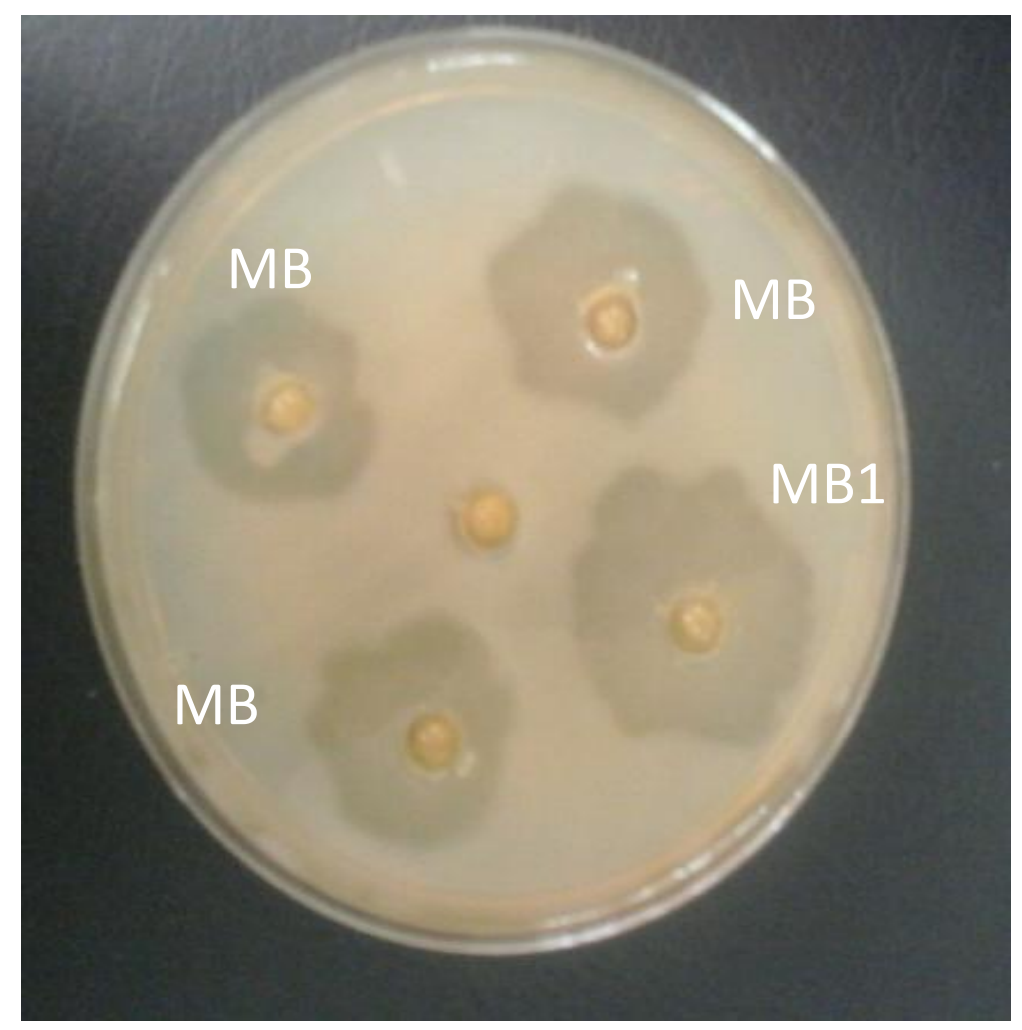

In conclusion, results reported in the present study on marine bacterial isolates have given various insights into the ecology of microorganisms in aquaculture. Preliminary screenings of 13 bacterial isolates have given a brief idea of some of their biotechnological abilities. The potential capabilities of some isolates to produce extracellular protease, lipase and antibacterial activities and to degrade crude oil make them promising for aquaculture applications. Further study is needed to characterize such activity and to identify the promising isolates.

\section{Acknowledgement}

Sincerely thanks to Marine Microbiology $\mathrm{Lab}$ at the National Institute of Oceanography and Fisheries, Alexandria, Egypt and Functional Foods and
Nutracuticals Laboratory (FFNL). The author thanks his respective managements for encouragement, facilities and support.

\section{References}

Ayed, L., Cheriaa, J., Laadhari, N., Cheree, A. and Bakhrouf, A. 2009. Biodegradation of crystal violet by an isolated Bacillus sp. Ann. Microbiol., 59: 267-272.

Baharum, S.N., Beng, E.K. and Mokhtar, M.A.A. 2010. Marine microorganisms: potential application and challenges. J. Biol. Sci., 10: 555564.

Baharum, S.N., Beng, E.K. and Mokhtar, M.A.A. 2010. Marine microorganisms: potential application and challenges. J. Biol. Sci., 10: 555564. 
Bull, A.T., Ward, A.C. and Goodfellow, M. 2000. Search and discovery strategies for biodiscovery: The paradigm shift. Microb. Mol. Biol Rev., 64: 573-606.

Chatellier, M.A., Jacky Bhagat, Karthik, K., Jaffar Hussain, A., and Jayaprakashvel. $\quad$ M. 2011. Deproteination of shrimp shell wastes using immobilized proteolytic marine bacteria. In: The Abstracts book of national level students seminar on biotechnology in daily life organized by department of biotechnology, AMET University Chennai on $10^{\text {th }}$ March 2011.

Debnath, M., Paul, A.K. and Bisen, P.S. 2007. Natural bioactive compounds and biotechnological potential of marine bacteria. Curr. Pharm. Biotechnol., 8(5): 253-60.

Dionisi, H.M., Lozada, M. and Olivera, N.L. 2012. Bioprospection of marine microorganisms: biotechnological applications and methods. Rev. Argent. Microbiol., 44(1): 49-60.

Jha, R.K. and Zi-Rong, X. 2004. Biomedical compounds from marine organisms. Mar. Drugs, 2: 123-146.

Lucas-Elio, P., Hernandez, P., SanchezAmat, A. and Solano, F. 2005. Purification and partial characterization of marinocine, a new broad-spectrum antibacterial protein produced by Marinomonas mediterranea. Biochimica Biophysica Acta, 1721: 193-203.

Manasi, N., Kaarthikeyan, C., Karthik, K.,
Jaffar Hussain, A., and Jayaprakashvel, M. 2011. Screening of bacteria isolated from marine environment for industrially important enzymes. In: National conference on marine explorations of the natural bioactive compounds from the marine resources" during Feb 10 and 11th 2011 organized by Department of Marine Science, Bharathidasan University. pp. 47-48.

Munn, C. 2004. Marine microbiology: Ecology and applications. London, BIOS Scientific Publ., p.282.

Nautiyal, C.S. and Mehta, S. 2001. An efficient method for qualitative screening of phosphate-solubilizing bacteria. Microbiol., 43: 51-56.

Ramesh, S. and Mathivanan, N. 2009. Screening of marine actinomycetes isolated from the Bay of Bengal, India for antimicrobial activity and industrial enzymes. World $J$. Microbiol. Biotechnol., 25: 21032111.

Singh, P.O., Parmar, D.J., and Pandya, A.V. 2015. Selective Screening of Potential Crude Oil Degrading Microbes from Crude Oil Contaminated Site. Int. Res. J. Environ. Sci., 4(1): 78-79.

Vijayan, N., Sagadevan, E., Arumugam, P., Jaffar Hussain, A., andJayaprakashvel, M. 2012. Screening of Marine bacteria for multiple Biotechnological applications. J. Acad. Indus. Res., Vol. $1(6), 348-354$.

\section{How to cite this article:}

Hala Ezzat Abou El-Hassayeb. 2016. Screening of Isolated Marine Bacteria for Multiple Biotechnological Applications. Int.J.Curr.Microbiol.App.Sci. 5(7): 424-430. doi: http://dx.doi.org/10.20546/ijcmas.2016.507.046 